\title{
DOAJ Media and Communications Journals: Business Models, Technical Aspects and Involvement in the International Scientific Process
}

\author{
Nataliia Trishchenko* \\ *Faculty of Journalism, New Media and Communication Theory Department, Lomonosov Moscow State University, Russian
} Federation

Abstract

\begin{abstract}
Despite the open science movement having been actively developing for nearly two decades, the scientific community is still wary of open access journals, especially if their status is not supported by the imprint of a big publishing house. This article discusses the results of research into the websites of media and communications journals registered in DOAJ (the Directory of Open Access Journals). This process facilitated a general understanding of how these journals function, what resources are used to support them and what future prospects they face. During the research, which was carried out from August to September 2018, the websites of 181 journals indexed in the DOAJ database were analysed. 64 journals (35\%) also agreed to participate in an anonymous survey, allowing additional information to be obtained. The results showed that almost a quarter of the analysed journals are indexed in the Web of Science and Scopus international citation databases, while $78 \%$ of the journals are associated with universities and scientific institutions that sponsor the publishing process. The majority of the journals registered in DOAJ are not run on a profit-making basis. High competition, lack of resources and administrative burdens are among the main obstacles to the development of Open Access journals.
\end{abstract}

Keywords: DOAJ; open access journals; media and communications; open science

Submitted: 30th October 2018

Accepted: 1st March 2019

\section{Introduction}

Scientific journals are generally thought of in terms of major publishing brands. However, due to the possibility of publishing scientific articles in the Internet without the need of printing a paper edition, the process of cooperation between editors and reviewers became much simpler and quicker. Consequently, small publishing houses, many of which do not even have an English edition, now have a chance to reach international audience, resulting in an extraordinary boost to the development, for example, of open access journals in Latin America, Spain and Portugal in recent decades (Shen, 2017).

However, without the creation of a database indexing publications from different areas of science and different regions of the world, it would be impossible for these local journals to enter the international market. One such database, launched by the Open Society Institute in 2003, is DOAJ (the Directory of Open Access Journals). As of September 2018, more than 12 thousand journals from 218 countries of the world are registered in DOAJ (together responsible for around 3.5 million articles).

Due to the DOAJ being considered as one of the most comprehensive open access journal databases in the world, which is supported by the results of the several research papers (Liljekvist et al., 2015), many analyses of the development of this publishing model have been carried out on the basis of its data. Extensive research into the quality of open content indexed in the DOAJ has also been carried out. For example, one of the first analyses of DOAJ journals in 2005 contained an examination of the same issues typically 
associated with journals listed in the database: data relevance, current accessibility and the openness of the materials on which it is based (Morris, 2006). At that time, the results of the research showed that access problems only affected $1.68 \%$ of the journals, proving DOAJ to be a valuable source of relevant primary sources. However, the results of a similar research carried in 2016 showed that around $5 \%$ of articles were unavailable using provided links, with another $25-26 \%$ of the articles being inaccessible if users were only able to obtain access through being redirected (Lightfoot, 2016).

The quality of the publications registered in DOAJ has also been the topic of considerable research in connection with the list of potentially predatory journals published by Jeffrey Beall (Beall, 2017). In particular, this issue was raised in an article devoted to analysing the presence of suspect publications in the Web of Science (WoS), Scopus and DOAJ, showing that $0.8 \%$ of such journals were indexed by WoS, $0.25 \%$ by Scopus and $15.15 \%$ by DOAJ (Somoza-Fernández et al., 2016).

A considerable proportion of the research into open-access articles is also based on WoS and Scopus data. In one of these articles, data is analysed regarding the proportion of open-access journals containing citations from these databases (Saadat \& Shabani, 2011). 321 out of 2953 journals (almost 11\%) were used in citations, the majority of these being in the field of mathematic science (53.1\%) articles and the smallest number in the humanities $(3.7 \%)$.

Some researchers have attempted to present the history of open access journals development into distinct periods on the basis of DOAJ data (Laakso, et al., 2011), as well as to track the development process and current state of open science in various countries, including Iran (Noruzi, 2007), China (Chen \& Ren, 2008), India (Sahoo, Mohanty \& Sahoo, 2017) and various African countries (Ezema \& Onyancha 2017).

The business models of open access journals have also been a widely-discussed topic in research papers. One such article describes the results of a comparison between the activities of small and large publishing companies, the latter defined as companies publishing more than 1000 articles or more than 50 journals per year (Polydoratou \& Schimmer, 2010). The most typical business models for the big publishing houses appear to be structured around article processing charges (APC), membership fees and advertising, while small publishers tend to be financed by sponsorship as well as paid subscriptions for the print version.

The most common approaches to DOAJ-related research are devoted to studying journals belonging to a particular area of study: here may be found previously published articles devoted to library science (Stephen \& Balamurugan, 2015; Pujar, 2014), chemistry (Nisha, Ahmad, 2014), agriculture (Murili 2018), religion (Loan et al., 2018), health and medicine (Mushtaq, Loan, Ali, 2018), zoology (Lihitkar, Lihitkar \& Waghmare, 2013), business and management (Agashe, Lihitkar \& Lihitkar, 2010), etc. The results of the mentioned studies show that the DOAJ is one of the most comprehensive databases of open access articles. The analyses of journals devoted to different subjects showed that materials are readily available (links are upto-date), as well as demonstrating that the publications are mainly aimed at English- and Spanish-speaking audience. The prevalence of British and Spanish journals is typical for the majority of subjects. However, some bigger publishing companies (particularly those focusing on religious topics) also contain a significant number of journals from Indonesia, where the practice of using the Open Journals System (OJS) and launching such platforms on the basis of universities is quite widespread. Only a small proportion of journals in each of the subject areas apply APC; instead, these smaller publishing houses typically operate within sponsorship programmes, using money provided by their university or scientific institution. 
This article is devoted to the area of media and mass communication journals, which remain underresearched, even though the area is one that is currently undergoing rapid development. The only research we were able to find on the topic was published in 2012; it presents the state of the field as it was five and a half years ago, this area of studies included only 102 journals, which is half as much as currently (Husain \& Nazim, 2013).

The aim of the research was to determine the specific features of the open access media and mass communication journals registered in DOAJ, to study their business models and technical aspects of their activities, as well as to understand the extent to which they are involved in international scientific processes.

\section{Methodology}

In order to carry out the analysis, open access journals listed in the "Communication. Mass media" category in the DOAJ catalogue were selected. At the beginning of the research, this category included 192 journals. Between August and September 2018, we studied the websites of the journals and collected information on specific features according to the following criteria:

1) Publisher (country of origin, publisher type);

2) Involvement of the journal in the international information space (language, whether they have DOI);

3) Sources of income;

4) Technical aspects of their activities;

5) Number of articles published per year;

6) Timeframe from submission of the article until its publication;

7) Indexing in WoS and Scopus.

The data was collected directly from DOAJ as well as from the individual journal websites. In cases where the DOAJ data was out of date, we used the information from the official journal websites. However, it was not possible to implement this in all cases, since around one third of all journals do not yet have a fully realised English-language version of the website. The data on indexing in WoS and Scopus was obtained directly from the databases.

The study of the 192 websites showed that 9 journals had already ceased their activities (either the webpage was unavailable or there were no new issues after 2016). One of the publications appeared to have been digitised and published as an archive with open licenses; another had been acquired by a large publisher and is now available via subscription. Thus, the final sample included 181 journals.

Additionally, letters were sent to the editors of all the selected journals with an invitation to participate in an anonymous survey. With the help of the survey we collected additional data on the year of launch of each of the journals, their target audience, the proportion of foreign readers and authors, sources of income and several other characteristics. In total, 64 journals participated in the survey. 


\section{Research results}

Business models

The results of DOAJ data and website analysis show that almost all open access media and communications journals are run on a non-profit basis: 173 journals (96\%) openly stated that they are not concerned with realising a profit, while $8(4 \%)$ belong to commercial publishing companies (though half of these have not monetised the projects in any way). The reason behind such findings is that publishers of open journals are primarily comprised of universities and scientific organisations (78\%), as well as non-profit organisations, i.e. scientific institutions and professional associations (13\%). As such, their aim is to distribute information and organise information exchange in certain communities, rather than to run a profitable business. Moreover, even independent publishers tend to be comprised of a group of enthusiasts or individual scientists, whose journals are financed on a crowdfunding or crowdsourcing basis. In two cases the owners of the journals were specialised government ministries. The type of publisher in accordance with the results of analysis of the websites and surveys are shown in Tables 1 and 2 respectively.

Table 1: Proportion of different types of publishers out of all journals studied (data was gained as a result of analysis of 181 journals' websites)

\begin{tabular}{|l|l|l|}
\hline Organisation type & Number of journals & Share (\%) \\
\hline Scientific organisation & 141 & 78 \\
\hline Non-profit organisation & 23 & 13 \\
\hline Independent publisher & 13 & 7 \\
\hline Other & 4 & 2 \\
\hline
\end{tabular}

Table 2: Proportion of different types of publishers out of all journals studied (data was gained as a result of anonymous survey with 64 participants)

\begin{tabular}{|l|l|l|}
\hline Organisation type & Number of journals & Share (\%) \\
\hline Scientific organisation & 50 & 78 \\
\hline Non-profit organisation & 8 & 13 \\
\hline Independent publisher & 4 & 6 \\
\hline Other & 2 & 3 \\
\hline
\end{tabular}

Only nine journals (5\%) charge APC, varying from 60 EUR (Indonesian journals) to 1100 EUR. One journal requires the authors to pay not in the form of APC, but instead to provide a 450 USD donation (for 3 authors, 
with an additional payment of 150 USD for each additional author). Two of the journals also demand a significant payment for publishing expenses ${ }^{1}$.

Four of the journals presented special editions on their websites, which were probably the result of sponsorship. Two more journals place advertising on their websites, while six aim to earn money through their print version (by subscription) or offer a print-on-demand option. Furthermore, two journals are financed by consortium with membership fees from universities.

We can state with certainty that 151 journals (83\%) function according to a sponsorship model (mainly by scientific organisations) as is directly stated on their websites. Another 19 journals (11\%) do not have a clearly stated source of income. As determined by the data on the respective websites, 11 journals use other financial instruments: donations, advertisement, special editions, paid subscription for the print version.

The survey results gave a more detailed picture of the different types of funding: five journals charge for article submission, while another five journals are financed through crowdfunding. Seven journals offer additional services to their authors, which serve as an income source. The more detailed information is presented in the Table 3 below.

Table 3: Sources of income for open access journals. Data was obtained as a result of an anonymous survey having 64 participants (participants could choose several answers).

\begin{tabular}{|l|l|l|}
\hline Sources of open access journals income & Number of journals & Share (\%) \\
\hline Sponsorship & 30 & 47 \\
\hline None & 10 & 16 \\
\hline APC & 7 & 11 \\
\hline Additional services & 7 & 11 \\
\hline Consortium investments & 6 & 9 \\
\hline Submission charges & 5 & 8 \\
\hline Crowdfunding & 5 & 8 \\
\hline Special issues & 4 & 6 \\
\hline Other & 3 & 5 \\
\hline Governmental grant & 2 & 3 \\
\hline Advertising & 1 & 2 \\
\hline Crowdsourcing & 1 & 2 \\
\hline Founders & 1 & 2 \\
\hline Publishing service & 1 & 2 \\
\hline
\end{tabular}

Business models are often combined, since the majority of the journals (judging by the appearance of the websites) function under quite challenging financial conditions and are looking for any opportunities that may help to support their projects. Almost $16 \%$ of the journals responded that they do not have sources of profit. However, on the basis of other replies, it may be concluded that they also use a sponsorship model,

${ }^{1}$ Data is provided in accordance with information from DOAJ and websites of the journals; however, in several cases DOAJ data was incorrect, while in others it was difficult to confirm if there had been any payments due to partial or total absence of an English version of the websites. 
though in place of financial support they may use the time of the employees of the sponsoring company, its servers, technical support, etc.

The survey also allowed general information to be collected relating to the structure of expenses. 34 out of 64 journals (53\%) provide publishing services without any special financial support. 49 journals $(77 \%)$ receive reviews for free, while 24 (37.55\%) receive free technical support, meaning that they mainly use the resources of a university or other founding organisation. The main expenses include salaries of the responsible secretary, editor and translator; hosting and domain name payments; identifiers, and publishing a printed version of a journal.

\section{Technical aspects of activities}

An overwhelming majority of the journals (70\%) use the Open Journals System (OJS); the relevant data is shown in Table 4. In $12 \%$ of the cases, the platform cannot be defined, which probably means that it has been created internally (the survey results show that $6 \%$ of the journals use software that they created themselves). The second most popular product is Wordpress (3\%); no other solution was used by more than two journals (1\%). The survey results also show that $31 \%$ of the journals had been launched prior to 2000; it was the use of these free platforms (OJS and Wordpress) that made their expansion among an international audience possible.

Table 4: Proportion of software platforms used by the open access journals (results of studying the websites of 181 journals).

\begin{tabular}{|l|l|l|}
\hline Platform & Number of journals & Share (\%) \\
\hline OJS & 126 & 70 \\
\hline Other & 28 & 15 \\
\hline N/a & 21 & 12 \\
\hline Wordpress & 6 & 3 \\
\hline
\end{tabular}

Software also determines the most popular article format: $97 \%$ of journals publish their articles in PDF, while only $24 \%$ present an HTML version (Table 5). It should be mentioned that PDF files are less suitable for online reading and may make it harder to conduct a full-text search. Other used formats include XML, EPUB, Kindle and Daisy; however, these are quite rare (especially the last two). 
Table 5: Number of journals publishing their articles in a corresponding format (results of studying the websites of 181 journals).

\begin{tabular}{|l|l|l|}
\hline Format & Number of journals & Share (\%) \\
\hline PDF & 176 & 97 \\
\hline HTML & 44 & 24 \\
\hline EPUB & 11 & 6 \\
\hline XML & 9 & 5 \\
\hline
\end{tabular}

Open access journals are often criticised for the low quality of reviews as well as for publishing a greater number of articles than could feasibly be properly examined by any editorial board. The results of analysing the websites of the journals ${ }^{2}$ show that 157 of them (87\%) publish between 10 and 50 articles per year (Figure 1). It takes between 2.5 months (22\% of journals) and a year (4\%) for an article to be published following its submission; in $64 \%$ of cases, it takes between three and six months.

Figure 1: Journals by the number of articles per year - average index for years 2015-2017 (results of studying the websites of 181 journals)

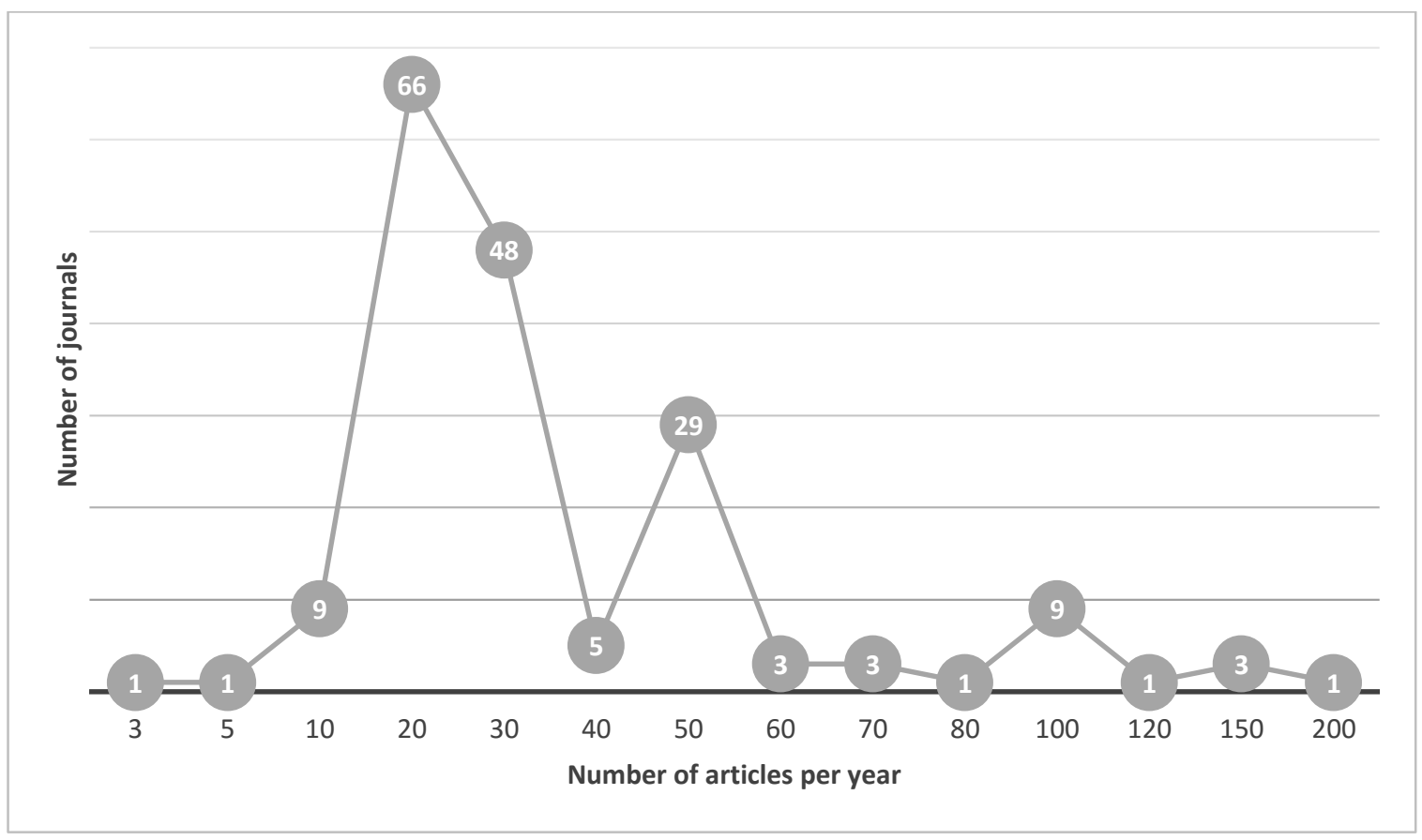

One of the journals presents an interesting example: having abandoned the practice of publishing periodical issues, it instead publishes articles immediately following the reviewing process without any correlation with specific dates. However, here the number of publications is similar to the other journals, with 80 articles being published in almost three years. The most popular publication frequency is 2 issues per year; this is

\footnotetext{
${ }^{2}$ During the data collection process the maximum number of articles published in a year was taken in round figures.
} 
used by $67 \%$ of the journals. $12 \%$ produce 3 issues per year, $10 \%$ only 1 issue, while $8 \%$ publish 4 issues per year.

The preferences for copyright licence type are as follows:

- Creative Commons Attribution (CC BY) - 61 journals (34\%);

- Creative Commons Attribution-Non-Commercial-No Derivatives (CC BY-NC-ND) - 52 journals (29\%);

- Creative Commons Attribution-Non-Commercial (CC BY-NC) - 38 journals (31\%);

- Creative Commons Attribution-Share Alike (CC BY-SA) - 13 journals (7\%);

- Creative Commons Attribution-Non-Commercial-Share Alike (CC BY-NC-SA) - 10 journals (6\%);

- Creative Commons Attribution-No Derivatives (CC BY-ND) - 4 journals (2\%);

- Own licencing - 3 journals (2 of these are comparable with CC BY, 1 with CC BY-NC).

5 out of 64 survey participants allow their authors to choose the type of a licence. One of the main reasons for using open licences for the journal (other than the necessity to keep the journals open) is that it was obligatory to list the license for being indexed in DOAJ and / or it was one of sponsors' requirements.

Involvement in the international scientific process

Open access media and mass communications journals enjoyed the most extensive development in Europe (73 journals) and in Latin American countries (61), as well as in Indonesia (21) ${ }^{3}$. This statement is supported both by the DOAJ data (Table 6) and by the survey results (Table 7). It is worth mentioning that 33 out of 73 European journals are published in Spain and Portugal, therefore also targeting the Iberoamerican scientific community.

Table 6: Regional distribution of journals (based on DOAJ data for 181 journals)

\begin{tabular}{|l|l|l|}
\hline Format & Number of journals & Share (\%) \\
\hline Europe & 73 & 40 \\
\hline Lain America & 61 & 34 \\
\hline Asia & 26 & 14 \\
\hline North America & 14 & 8 \\
\hline Australia & 6 & 3 \\
\hline Africa & 1 & 1 \\
\hline
\end{tabular}

\footnotetext{
${ }^{3}$ Results of the previously mentioned research done in 2012 do not include any information on Indonesian journals. It seems like at that time they had just started their development and targeted their local audience.
} 
Table 7: Regional distribution of journals (based on the survey among 64 journals).

\begin{tabular}{|l|l|l|}
\hline Format & Number of journals & Share (\%) \\
\hline Europe & 19 & 30 \\
\hline Lain America & 22 & 34 \\
\hline Asia & 16 & 25 \\
\hline North America & 5 & 8 \\
\hline Australia & 1 & 1.5 \\
\hline Africa & 1 & 1.5 \\
\hline
\end{tabular}

As a result, the most widespread languages are English (articles in English, according to DOAJ data, may be published in 103 out of 181 journals, i.e. 57\%), Spanish (72 journals, 40\%), Portuguese (58 journals, 32\%) and Indonesian (20 journals, 11\%). At the same time, only 100 journals (55\%) are published in one language, 51 journals (28\%) - in two languages (in English and in national language), while 30 (17\%) journals publish their articles in three or more languages. However, it is typically only the metadata of articles that is translated into additional languages; therefore, not everyone is able to read the whole article. The survey data showed a similar picture: in 38 journals out of 64 (59\%), it is possible to publish an article in English; however, only 12 journals publish their articles entirely in this language (19\%). The next most widespread languages are Spanish (24 journals, 44\%), Portuguese (18 journals, 28\%), Indonesian and French ( 9 journals or $14 \%$ each).

In comparison with 2012, the proportion of journals in which it is possible to publish an article in Spanish and in Portuguese has grown significantly (from $15 \%$ to $30 \%$ and from $20 \%$ to $32 \%$ respectively). Indonesian has become the fourth most widespread language - in 2012 it was not mentioned at all.

The language barrier is one of the main obstacles for the expansion of content published in open access journals within the international scientific community. Only in 43 journals are articles published solely in the English language; in 60 journals, some of the articles are published in English, while in other 79 journals, the articles are published in other languages. The metadata situation is a bit more optimistic. Here, 169 journals publish their metadata in English, three journals translate some of their articles, while only nine journals do not translate their metadata. The situation with the websites of the journals is quite similar: 121 journals have an English version, 43 are partially translated (the sections with general information about the journal and instructions for authors), while only 17 websites do not have any English interface elements.

The survey included a question on the proportion of foreign authors and foreign readership of the researched journals. The results showed that for almost a third of journals (28\%), the proportion of authors from foreign countries exceeds $50 \%$, while in $36 \%$ of cases the proportion of foreign authors is less than $15 \%$ (Table 8 ). The proportion of foreign readers is probably higher; however, not all journals track this data: $31 \%$ of the journals were not able to provide such information (Table 9). 
Table 8: Proportion of foreign authors in open access journals (based on the survey responses of 64 journals)

\begin{tabular}{|l|l|l|}
\hline Proportion of foreign authors & Number of journals & $\begin{array}{l}\text { Proportion of journals } \\
(\%)\end{array}$ \\
\hline $0-5 \%$ & 10 & 16 \\
\hline $5-15 \%$ & 13 & 20 \\
\hline $15-30 \%$ & 13 & 20 \\
\hline $30-50 \%$ & 7 & 11 \\
\hline $50-70 \%$ & 6 & 9 \\
\hline$>70 \%$ & 12 & 19 \\
\hline Unknown & 3 & 5 \\
\hline
\end{tabular}

Table 9: Proportion of international readership of open access journals (based on the survey among 64 journals)

\begin{tabular}{|l|l|l|}
\hline Proportion of foreign readers & Number of journals & $\begin{array}{l}\text { Proportion of journals } \\
(\%)\end{array}$ \\
\hline $0-5 \%$ & 4 & 6 \\
\hline $5-15 \%$ & 5 & 8 \\
\hline $15-30 \%$ & 10 & 16 \\
\hline $30-50 \%$ & 6 & 9 \\
\hline $50-70 \%$ & 7 & 11 \\
\hline$>70 \%$ & 12 & 19 \\
\hline Unknown & 20 & 31 \\
\hline
\end{tabular}

Currently, one of the primary instruments used to search and identify scientific articles is the Digital Object Identifier system (DOI). For this reason, the presence of a DOI was considered to be one of the characteristics indicating the involvement of journals in the international scientific process. According to the collected data, only 119 out of 181 journals (66\%) assign a DOI to their articles. However, the survey results showed that several journals plan to introduce such a practice in the near future and see it as an important part of their further development.

One of the key indicators of integration in the international scientific process is indexing in WoS and / or Scopus databases. As part of this research, it was examined how the considered journals comply with this criterion (data was gained directly from the scientometric databases). 37 journals (20\%) are indexed in WoS ( 1 of these is included in Social Sciences Citation Index (SSCI), while the remainder are indexed in the WoS Emerging Sources Citation Index (ESCI)); 21 journals (12\%) are indexed in Scopus. 12 journals (7\%) are indexed in both databases. All in all, 46 journals (25.4\%) are included in international scientific citation databases (Table 10). 
Table 10: Indexing of open access journals in WoS and Scopus: only WoS, only Scopus and both databases (data from scientometric databases for 181 journals)

\begin{tabular}{|l|l|l|}
\hline Database & Number of journals & Share (\%) \\
\hline WoS & 25 & 14 \\
\hline Scopus & 9 & 5 \\
\hline Scopus and WoS & 12 & 7 \\
\hline None & 135 & 74 \\
\hline
\end{tabular}

Out of journals indexed in WoS and Scopus, 25 (54\%) work on OJS; in 36 journals (78\%), the articles are published in English language; in 26 (52\%), articles are published in Spanish (16 journals or 35\% are also published in Spain). Only $2 \%$ of the journals publish more than 70 articles per year, while $65 \%$ publish no more than 30 articles. $65 \%$ of the journals are published by universities and non-profit organisations, while $17.5 \%$ are published independently. Out of the mentioned journals, only 2 charge APC. One of these did not apply such a charge in 2018; another charged 800 EUR. However, two additional journals currently belong to big international publishers and may introduce APC in the future.

The respondents of the survey also mentioned EBSCO as one of the main scientific databases together with WoS and Scopus; however, DOAJ was most frequently referred to as the most comprehensive catalogue of open access journals ${ }^{4}$. Out of other databases that index journals, at least several publications mentioned Google Scholar, ProQuest, Open AIRE, BASE, Latindex, Academic, Dialnet, Ulrich's, Erich Plus, Redalyc, MIAR, SciELO, Redib, Dialnet and a couple of other less known resources that primarily target a particular region.

\section{Conclusions and discussion}

The emergence of a diverse network of open access journals mainly published by universities and targeting an international audience would be impossible without the Internet as well as cheap, ready-to-use software, such as the OJS platform, which is used by two thirds of all the journals. At the same time, a considerable number of the journals were launched prior to the digital era; for these, transition into an online platform became their next stage of development, since staying on the subscription model left almost no chance of getting the type of attention these journals currently receive.

The majority of the journals registered in the DOAJ are not aimed at receiving profit. As the results of the survey and analysis of the websites showed, these do not even consider the possibility of making a profit because this is not their aim. It is worth mentioning that only one out of 64 journals that participated in the survey referred to itself as profitable. At the same time, one of the current burning issues for many journals is a lack of resources. The limited number of journals using DOIs may be explained by the fact that the university journals usually have a very limited funding, which also tends to affect the salaries of the editor, the responsible secretary and technical support.

\footnotetext{
${ }^{4}$ In the poll invitations the criteria for choosing the journals for the research were not mentioned.
} 
While answering the question about the future goals of the journal and what changes they would like to implement, several participants underlined the necessity of increased funding, as well as the need to start paying editors and reviewers. Moreover, many respondents believe that it may be possible to attract additional resources after being included in such databases as Scopus and WoS; therefore, indexing in these databases becomes one of the main priorities for any "small" journal. Thus, matters of prestige, as well as administrative pressure on scientists play an important role in this segment of scientific publication, which has to compete with big market players. However, university journals also have many advantages, since they do not charge APC, the period between the article submission and its publication is much shorter, and authors have an opportunity to publish their articles in multiple languages.

Stiff competition and lack of resources force open access journals to search for other development approaches. The editor of the journal that switched to a subscription model under the management of a bigger imprint commented that their journal needed to develop, but the scientific community was not ready to provide their best articles to an unknown publishing house. As a result, the only chance to provide the authors with what they needed was to sacrifice the open access model.

The manager of another open access journal (which is indexed in Scopus) also mentioned that several journals are looking into a similar development model, since the university is not even funding the assignment of DOI, let alone the salaries of the editorial's employees. Therefore, the whole publication process relies on the good will of employees, who start to think about the possibility of ensuring further development of the project without institutional funding. It should be mentioned that four of the investigated journals that currently belong to international publishing houses were originally included in DOAJ as university journals and probably were able to develop to a level where they could attract bigger market players and come under their control.

Of course, not all open access journals are of good quality; however, at least one quarter of them is indexed in scientometric databases, which demonstrates their perceived quality in the eyes of the international scientific community. University open access journals could become an alternative to the existing publishing industry, especially since editors and reviewers are often the same people. However, in order to achieve this, it is vital to reorganise resources, providing the university journals with the necessary development opportunities - in the first place, technological. Nevertheless, the programmes of transferring to the open access models in Europe and the USA mainly target the development of repositories ("green" open access) and the motivation of the bigger publishers to transfer to a new model. Despite their potential to become an alternative platform for the exchange of scientific research, university journals tend to stay under the radar.

In the current situation, financial problems are not the only developmental obstacle for this segment of scientific journals. As long as scientists themselves place the primary emphasis on the imprint and the prestige of the big publishing houses, there will still be a place for subscription journals and 5000 EUR APC. There is no doubt that universities and scientific organisations are also not entirely selfless, since they have their own motives in publishing journals, which allow them to promote their organisation and ensure the dissemination of the results of their scientists' work in order to obtain a return on their investments. However, it is likely that this motivation is more in the interest of societies that finance scientific activities and have the right of access to the results, than in the case of major for-profit publishers. 


\section{References}

Agashe A., Lihitkar, R., Lihitkar, S. (2010). Free online journals on business and management in directory of open access journals (DOAJ). SRELS Journal of Information Management 47(1), 41-58. http://www.srels.org/index.php/sjim/article/view/44939.

Beall, J. (2017). What I learned from predatory publishers. Biochemia Medica 27(2), 273-278. https://doi.org/10.11613/bm.2017.029.

Chen, W., Ren, S. (2008). Evolution of Open Access Publishing in Chinese Scientific Journals. Learned Publishing 21(2), 140-152.

Ezema, I., Onyancha, O. (2017). Open access publishing in Africa: Advancing research outputs to global visibility. African Journal of Library Archives and Information Science 27, 97-115. https://www.researchgate.net/publication/322340214_Open_access_publishing_in_Africa_Advanc ing_research_outputs_to_global_visibility

Husain, S., M. Nazim, M. (2013). Analysis of Open Access Scholarly Journals in Media \& Communication. DESIDOC Journal of Library \& Information Technology 33(5), 405-411.

Laakso, M., Welling, P., Bukvova, H., Nyman, L., Björk, B.-C., Hedlund, T. (2011). The Development of Open Access Journal Publishing from 1993 to 2009. PLOS One 6(6): e20961. https://doi.org/10.1371/journal.pone.0020961.

Lightfoot, E. (2016). The persistence of open access electronic journals. New Library World 117 (11/12), 746-755. https://doi.org/10.1108/NLW-08-2016-0056.

Lihitkar, R., Lihitkar, S., Waghmare, P. (2013). Open Access Zoology Journals on DOAJ: An analytical Study. International Journal of Life Sciences 1(4), pp. 321-327. http://oaji.net/articles/2014/7361400753563.pdf

Liljekvist, M., Andresen, K., Pommergaard, H., Rosenberg, J. (2015). For 481 biomedical open access journals, articles are not searchable in the Directory of Open Access Journals nor in conventional biomedical databases. Peer] 3:e972. https://doi.org/10.7717/peerj.972.

Loan, F., Quraishi, J., Refhat-un-Nisa, Wasim, H. (2018). Open Access Religious Journals - An Analytical Study of the DOAJ. Library Philosophy and Practice. https://digitalcommons.unl.edu/cgi/viewcontent.cgi?article=4923\&context=libphilprac

Morris, S. (2006). When is a journal not a journal? A closer look at the DOAJ. Learned Publishing 19(1), 7376. https://doi.org/10.1087/095315106775122565.

Murili. (2018). Open access journals in library and information science: a study. DESIDOC Journal of Library \& Information Technology 38(5), 354-360, https://doi.org/10.14429/djlit.38.5.13114

Mushtaq R., Loan M., Ali M. (2017). Open Access Health and Medicine Journals - An Informative Study. Webology 14(2). http://www.webology.org/2017/v14n2/a160.pdf.

Nisha, F., Ahmad, H. (2014). Analysis of Open Access Scholarly Journals in Chemistry. Library Philosophy and Practice. http://digitalcommons.unl.edu/libphilprac/1100

Noruzi, A. (2007). Open Access Journals: A Pathway to Scientific Information in Iran. Proceedings of the ELPUB2007 Conference on Electronic Publishing. Vienna: Austria.

Polydoratou, P., Schimmer, R. (2010). Income sources as underlying business models' attributes for scholarly journals: preliminary findings from analysing open access journals' data. ELPUB 2010 (14th 
International Conference Electronic Publishing).

https://helda.helsinki.fi/bitstream/handle/10227/599/polydoratou_schimmer.pdf?sequence=37

Pujar, S. (2014). Open access journals in library and information science: a study. Annals of Library and $\begin{array}{llrl}\text { Information Studies } \quad \text { (ALIS) } & \text { 61(3), }\end{array}$ http://op.niscair.res.in/index.php/ALIS/article/view/7068

Saadat, R., Shabani, A. (2011). Investigating the Citations Received by Journals of Directory of Open Access Journals from ISI Web of Science's Articles. International Journal of Information Science and Management 9(1), 57-74.

Sahoo, J., Mohanty, B., Sahoo, L. (2017). Indian contribution to open access scholarly publishing in DOAJ. Library Philosophy and Practice. http://digitalcommons.unl.edu/libphilprac/1567/

Shen, C. (2017). Open Access Scholarly Journal Publishing in Chinese. Publications 5(4), 22. https://doi.org/10.3390/publications5040022.

Somoza-Fernández, M., Rodríguez-Gairín, J.M., Urbano, C. (2016). Presence of alleged predatory journals in bibliographic databases: Analysis of Beall's list. El Profesional de la Información 25(5), 730-737. https://doi.org/10.3145/epi.2016.sep.03.

Stephen, G., Balamurugan, T. (2015). Open Access Literature Productivity of Library and Information Science: A DOAJ Perspective. In S. Thanuskodi (Ed.), Handbook of Research on Inventive Digital Tools for Collection Management and Development in Modern Libraries, pp. 153-169. Hershey, PA: IGI Global. https://doi.org/10.4018/978-1-4666-8178-1.ch010 